\title{
FATORES DE INFLUÊNCIA PARA OTIMIZAÇÃO DO NIVEL DE EMISSÃO IRRADIADA DO SISTEMA DE IGNIÇÃO
}

\author{
Marcelo Sartori Campi \\ Robert Bosch Ltda. \\ E-mail: marcelo.campi@br.bosch.com
}

\section{RESUMO}

Este trabalho avalia o sistema de ignição e seus componentes com relação a EMC , principalmente a emissão irradiada e os fatores principais de influencia.

Atualmente existe uma tendência de aumento da severidade em relação às medições veiculares e particularmente os componentes do sistema de ignição composto de bobina de ignição, velas e cabos de ignição tem um peso significativo.

Através da analise conceitual previa identificamos as alavancas para atenuar o nível de emissão irradiada considerando uma visão do sistema e não somente de forma isolada de cada componente.

Serão apresentados os resultados dos ensaios em laboratórios credenciados bem como a análise critica dos resultados.

Desta forma é possível ter uma visão mais abrangente do sistema de ignição com relação a EMC e exemplos de valores quantitativos de cada alteração nos componentes propostos.

O objetivo final é verificar as possibilidades atuais para otimizar o nível de emissão irradiada via sistema de ignição.

\section{INTRODUÇÃO}

\section{INFORMAÇÕES GERAIS}

\subsection{Sistema de Ignição}

O sistema de ignição (figura 1) composto por bobina de ignição, vela de ignição, cabos de ignição e estagio de potencia contribui geralmente de forma significativa para os níveis de emissão irradiada.

Devido à complexidade dos componentes envolvidos não temos ferramentas de simulação que possam determinar valores com precisão.

Desta forma é necessário determinar os fatores principais de influencia do sistema de ignição e medidas efetivas para atenuação do nível de emissão irradiada. 


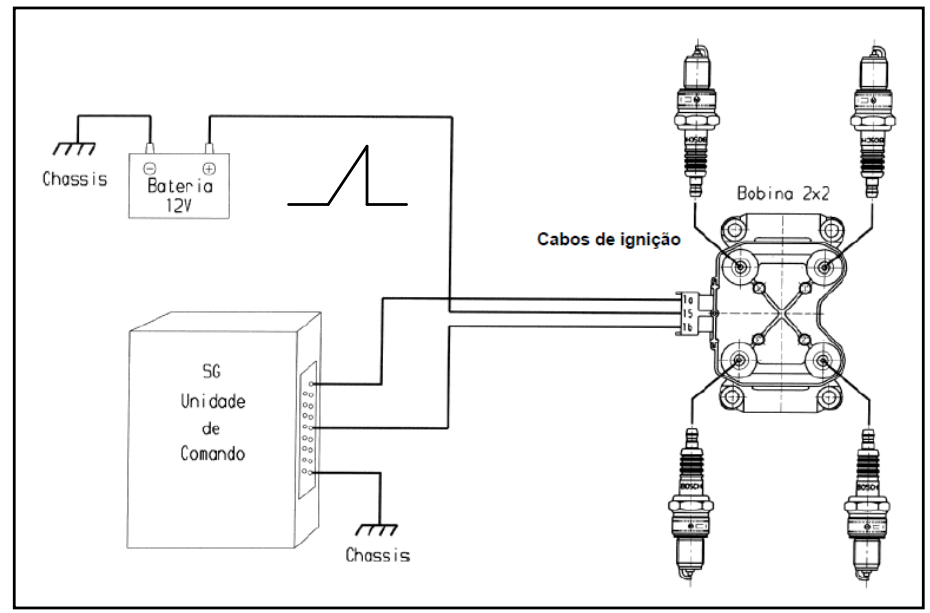

Figura 1. Visão geral dos componentes do sistema de ignição. (Exemplo: bobina 2x2 )

Devido ao chaveamento da corrente do primário através da unidade de comando, a alta tensão é induzida no secundário da bobina (da ordem de $30 \mathrm{kV}$ ) e consequentemente ocorre a faísca na vela de ignição após superar a tensão de ruptura.

Desta forma os elementos para a emissão eletromagnética estão presentes : variação da corrente do primário com tempos de transição muito pequenos ( rise / falltime ); variação abrupta da corrente e tensão do secundário na vela de ignição produzindo um amplo espectro de frequências e os condutores que geralmente tem um comprimento significativo ( acima de $1 \mathrm{~m})$.

A figura 2 mostra como ocorre o mecanismo de propagação até o receptor.

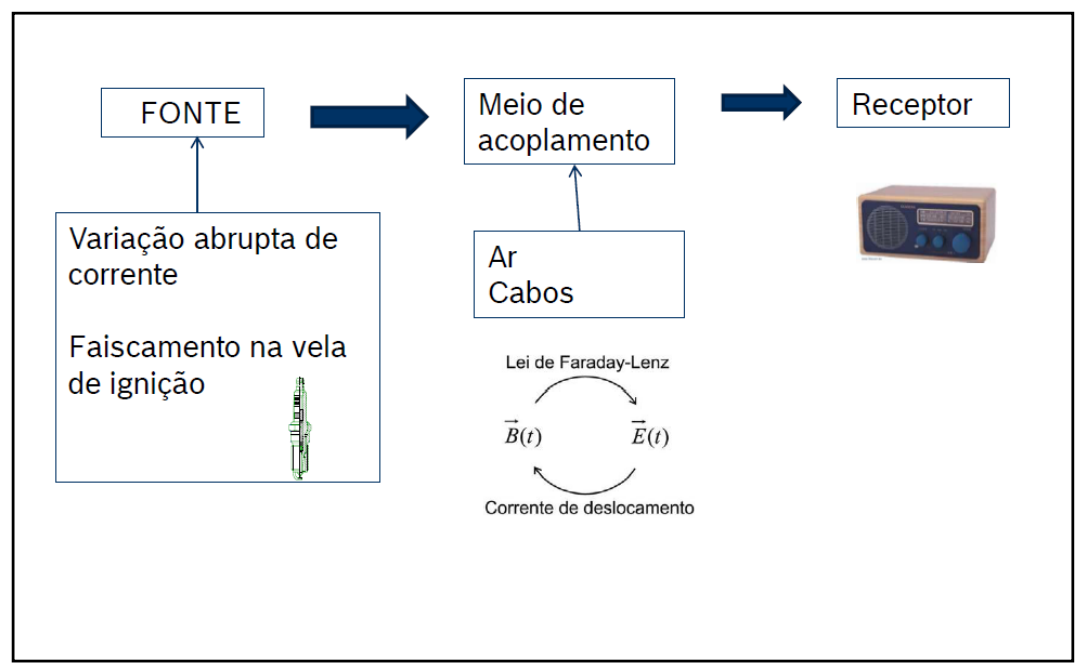

Figura 2. Mecanismo de propagação da onda eletromagnética no sistema de ignição

1.2 Medições da emissão irradiada

Para verificação do nível de emissão irradiada do sistema de ignição foi usada como base a configuração conforme norma CISPR25. ( figura 3 ) 

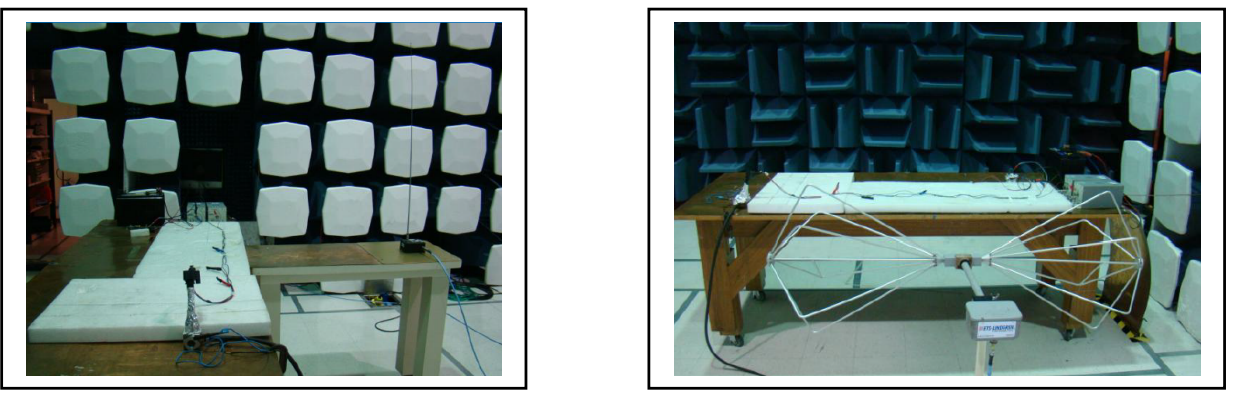

Figura 3 : Ensaio de emissão irradiada. Configuração usando antenas monopolo e biconica.

Para a realização do ensaio, foi utilizada uma bobina de ignição do tipo 1x1 e 2x2, ou seja uma faísca por cilindro ou dupla, de acordo com os parâmetros abaixo :

Tensão de alimentação : $13,50 \mathrm{~V}$

Frequência de operação : $50 \mathrm{~Hz}$

Corrente primário (pico) : 7,3A

Tensão de centelhamento : $15 \mathrm{kV}$

Detector : Peak e QuasiPeak

Comprimento dos cabos : $1,50 \mathrm{~m}$

Distancia da antena $\quad: 1 \mathrm{~m}$

\subsection{Técnicas para atenuação}

Idealmente devemos atenuar a emissão na própria fonte geradora ou tornar o acoplamento via meio ineficiente.

Por outro lado, não é possível reduzir a performance do produto já que compromete o desempenho do motor. A seguir temos os fatores principais de influencia para atenuar o nível de emissão irradiado.

\subsubsection{Elemento supressor montado na bobina de ignição do tipo 1x1}

O circuito elétrico equivalente do supressor utilizado em bobinas do tipo $1 \mathrm{x} 1$ pode ser visto conforme a figura 4 :

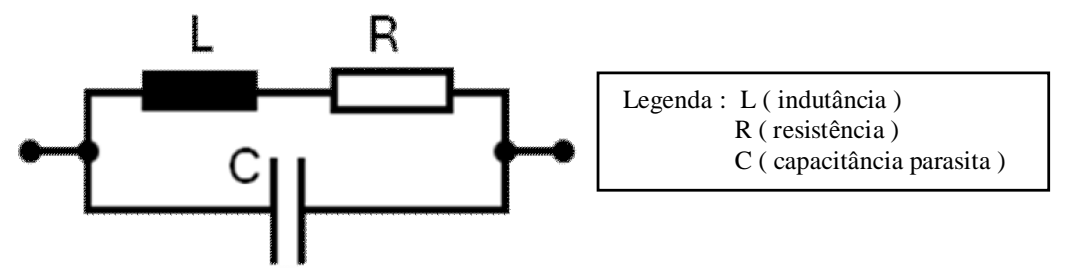

Figura 4. Circuito elétrico equivalente do supressor 
A principio este componente tem comportamento puramente resistivo quando a frequência é baixa, porém apesar da baixa indutância e capacitância parasitas presentes, estes fatores se tornam relevantes em alta frequência.

Através do incremento da resistência e indutância pode-se determinar uma impedância que tenha um nível otimizado para atenuar a emissão na faixa de FM.

Atualmente o padrão é utilizar resistência de $1 \mathrm{k} \Omega$. Se o supressor é montado com varias camadas de fios enrolados como em uma bobina, a indutância é da ordem de $1 \mu \mathrm{H}$.

Já a capacitância parasita varia em função da construção do supressor.

O valor máximo da impedância ocorre na frequência de ressonância o que multiplica o valor da resistência inicial de forma significativa.

A inclusão do supressor no secundário da bobina atenua a emissão gerada pela vela e bobina.

\subsubsection{Capacitor}

A inclusão de um capacitor no circuito primário da bobina de ignição pode atenuar principalmente a emissão na faixa de AM já que temos um filtro para baixa frequências como mostrado na figura 5 .

O efeito do capacitor em medições de emissão conduzida mostrou um efeito significativo

Desta forma será avaliado a sua influencia para emissão irradiada.

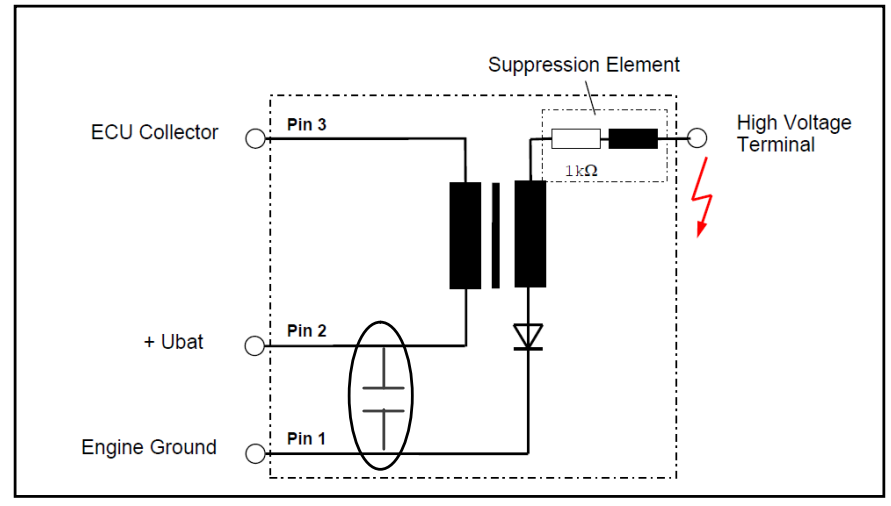

Figura 5. Circuito elétrico equivalente da bobina com capacitor integrado no primário.

\subsubsection{Vela de ignição}

Existem no mercado diferentes tipos de vela , dimensional e característica de supressão.

Caso exista um deficiência na isolação da mesma , pode afetar o nível de emissão.

Para avaliar o grau de contribuição foi realizado ensaio utilizando como alternativa um conjunto de diodos zener para simular a tensão de queima da vela após ruptura do dielétrico.

( figura 6) 


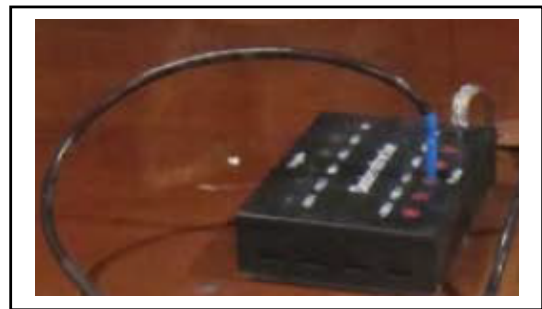

Figura 6. Dispositivo montado com banco de diodos zener $(\mathrm{Uz}=1000 \mathrm{~V})$

\subsubsection{Cabos de ignição}

Os cabos de ignição são usados no sistema com bobina $2 \times 2$ e a sua posição e comprimento são determinados devido a configuração de cada aplicação.

Existe neste caso pouca margem para atuação, sendo que o cabo de tipo indutivo foi avaliado em relação ao puramente resistivo para efeito de comparação.

\section{RESULTADOS}

Os resultados apresentados foram realizados em laboratórios credenciados.

A tabela 1 apresenta o resumo dos testes efetuados.

Sistema com bobina $1 \mathrm{x} 1$;

\begin{tabular}{|c|c|c|c|c|c|c|}
\hline Teste Nr. & Resistor & Capacitor & Frequencia (Hz) & Peak max (dB $\mu \mathrm{V})$ & QuasiPeak max (dBuV) & Redução Peak (dBuV) \\
\hline 1 & $1 \mathrm{k} \Omega$ & NA & $150 \mathrm{k}-30 \mathrm{M}$ & 89 & 79 & referencia \\
\hline 2 & $2 \mathrm{k} \Omega$ & NA & $150 \mathrm{k}-30 \mathrm{M}$ & 87 & & -2 \\
\hline 3 & $2 \mathrm{k} \Omega$ & $1 \mathrm{uF}($ distante) & $150 \mathrm{k}-30 \mathrm{M}$ & 87 & 76 & -2 \\
\hline 5 & $1 \mathrm{k} \Omega$ & NA & $30 \mathrm{M}-200 \mathrm{M}$ & 80 & & referencia \\
\hline 6 & $2 \mathrm{k} \Omega$ & NA & $30 \mathrm{M}-200 \mathrm{M}$ & 75 & & -5 \\
\hline 7 & $2 \mathrm{k} \Omega$ & $1 \mathrm{uF}($ distante) & $30 \mathrm{M}-200 \mathrm{M}$ & 75 & & -5 \\
\hline 8 & $2 \mathrm{k} \Omega$ & $1 \mathrm{uF}($ proximo) & $30 \mathrm{M}-200 \mathrm{M}$ & 74 & & -6 \\
\hline 9 & $2 \mathrm{k} \Omega$ & $2 \mathrm{uF}$ & $30 \mathrm{M}-200 \mathrm{M}$ & 73 & & -7 \\
\hline 10 & $1 \mathrm{k}+2 \mathrm{k}($ serie) & NA & $30 \mathrm{M}-200 \mathrm{M}$ & 71 & & -9 \\
\hline
\end{tabular}

Tabela 1 : Teste de emissão irradiada ; polarização vertical ( range 30M-200M Hz)

Como exemplo temos os resultados comparativos com o resistor de $1 \mathrm{k} \Omega$ e $2 \mathrm{k} \Omega$ conforme figura7. 


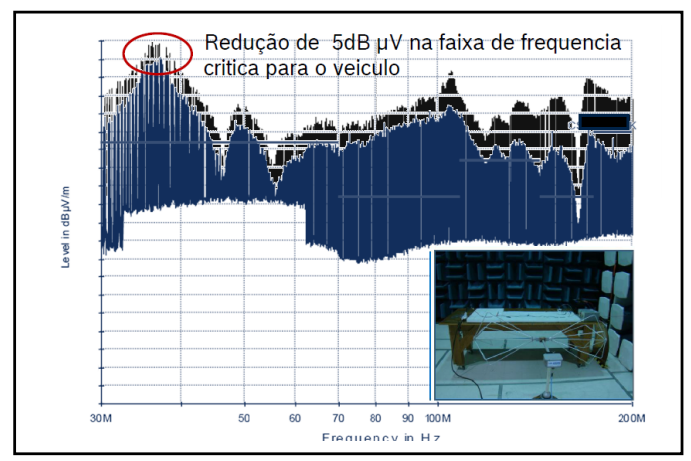

Figura 7. Teste de emissão irradiada utilizando resistores de $1 \mathrm{k} \Omega$ e $2 \mathrm{k} \Omega$

Para avaliação da influencia dos cabos de ignição e vela de ignição foi testada a bobina 2x2 conforme tabela 2 .

\begin{tabular}{|c|c|c|c|c|c|}
\hline Teste Nr. & carga & cabos ignição & Frequencia $(\mathrm{Hz})$ & QuasiPeak max $(\mathrm{dB} \mu \mathrm{V})$ & Redução $(\mathrm{dBuV})$ \\
\hline 11 & vela de ignição & padrão & $530 \mathrm{k}-1,70 \mathrm{M}$ & 77 & referencia \\
\hline 12 & vela de ignição & blindados & $530 \mathrm{k}-1,70 \mathrm{M}$ & 45 & -32 \\
\hline 13 & diodo zener & padrão & $530 \mathrm{k}-1,70 \mathrm{M}$ & 35 & -42 \\
\hline 14 & vela de ignição & padrão & $45-200 \mathrm{M}$ & 38 & referencia \\
\hline 15 & vela de ignição & indutivo & $45-200 \mathrm{M}$ & 28 & -10 \\
\hline
\end{tabular}

Tabela 2 : Teste de emissão irradiada ; polarização horizontal ( range 45M-200M Hz)

Como pode ser observado, quando é utilizado um cabo de ignição blindado ( $\mathrm{R}=3 \mathrm{k} \Omega$ ) ou o bloco de diodos zener o nível de emissão é reduzido no mínimo em $32 \mathrm{~dB} \mu \mathrm{V}$ para um sistema com bobina $2 \times 2$.

A utilização do cabo indutivo também mostrou um resultado positivo, da ordem de $10 \mathrm{~dB} \mu \mathrm{V}$

\section{CONCLUSÃO}

A utilização de um capacitor no primário da bobina influencia ligeiramente o nivel de emissão irradiada (QP), mas não interfere no resultado na faixa de FM e frequência superior como já era esperado.

De forma análoga , a utilização do supressor com resistência maior não interfere no resultado na faixa de AM porem tem um efeito muito positivo na faixa de 30 a $200 \mathrm{MHz}$, principalmente onde temos uma condição critica em veiculo.

A sua implementação é factível e de baixo impacto para o design da bobina, desde que exista uma margem na performance no produto para compensar as perdas ôhmicas inerentes a esta modificação.

A definição da vela de ignição e respectivo cabo de ignição devem ter uma atenção especial já que contribuem com cerca de 30 a $40 \mathrm{~dB}$ na faixa de AM para sistemas com bobinas 2x2. Desta forma , os fatores de influencia para emissão do sistema de ignição e seus respectivos pesos estão descritos e para cada aplicação deve ser feita a devida analise da relação custo $\mathrm{x}$ beneficio e a combinação dos mesmos quando aplicável para restringir o nível máximo de emissão irradiada. 


\section{REFERÊNCIAS}

[1] Documentos internos Bosch 